\title{
On an integral equation arising in the transport of radiation through a slab involving internal reflection
}

\section{Generalisation and numerical results for the Fresnel case}

M.M.R. Williams ${ }^{\mathrm{a}}$

Computational Physics and Geophysics, Department of Earth Science and Engineering, Imperial College of Science, Technology and Engineering, Prince Consort Road, London, SW7 2BP, UK

Eur. Phys. J. B 53, 245 (2006)

Received 3 November 2006

Published online 17 November 2006 - (C) EDP Sciences, Società Italiana di Fisica, Springer-Verlag 2006

An error occurred in the published article. In page 252, the columns in Table 5 headed $T_{s}$ and $T_{d}$ should be multiplied by 0.1 .

\footnotetext{
${ }^{a}$ e-mail: mmrw@nuclear-energy.demon.co.uk
} 